\title{
Radiation Protection for Lunar Mission Scenarios
}

\author{
Martha S. Clowdsley* \\ NASA Langley Research Center, Hampton, VA, 2368-2199 \\ John E. Nealy ${ }^{\dagger}$ \\ Old Dominion University, Norfolk, VA, 23529 \\ John W. Wilson and Brooke M. Anderson ${ }^{\S}$ \\ NASA Langley Research Center, Hampton, VA, 2368-2199 \\ and \\ Mark S. Anderson $^{* *}$ and Shawn A. Krizan ${ }^{\dagger \dagger}$ \\ Analytical Mechanics Associates, Hampton, VA, 23666
}

\begin{abstract}
Preliminary analyses of shielding requirements to protect astronauts from the harmful effects of radiation on both short-term and long-term lunar missions have been performed. Shielding needs for both solar particle events (SPEs) and galactic cosmic ray (GCR) exposure are discussed for transit vehicles and surface habitats. This work was performed under the aegis of two NASA initiatives. The first study was an architecture trade study led by Langley Research Center (LaRC) in which a broad range of vehicle types and mission scenarios were compared. The radiation analysis for this study primarily focused on the additional shielding mass required to protect astronauts from the rare occurrence of a large SPE. The second study, led by Johnson Space Center (JSC), involved the design of lunar habitats. Researchers at LaRC were asked to evaluate the changes to mission architecture that would be needed if the surface stay were lengthened from a shorter mission duration of 30 to 90 days to a longer stay of 500 days. Here, the primary radiation concern was GCR exposure. The methods used for these studies as well as the resulting shielding recommendations are discussed. Recommendations are also made for more detailed analyses to minimize shielding mass, once preliminary vehicle and habitat designs have been completed. Here, methodologies are mapped out and available radiation analysis tools are described. Since, as yet, no dosimetric limits have been adopted for missions beyond low earth orbit (LEO), radiation exposures are compared to LEO limits. Uncertainties associated with the LEO career effective dose limits and the effects of lowering these limits on shielding mass are also discussed.
\end{abstract}

\section{Nomenclature}

$=$ dose

$=$ effective dose

$=$ dose equivalent calculated with a quality factor, $Q$

$=$ equivalent dose calculated with radiation weighting factors, $w_{r}$

$=$ linear energy transfer

$=$ quality factor for stochastic biological effects

\footnotetext{
${ }^{*}$ Research Physicist, Computational Structures and Materials Branch, MS 388.

${ }^{\dagger}$ Research Professor, Mathematics Department.

* Senior Research Scientist, Computational Structures and Materials Branch, MS 388.

$\S$ Aerospace Engineer, Structural and Thermal Systems Branch, MS 431.

${ }^{* *}$ Aerospace Engineer, 303 Butler Farm Road Suite 104A.

${ }^{\dagger}$ Aerospace Engineer, 303 Butler Farm Road Suite 104A.
}

1

American Institute of Aeronautics and Astronautics 


$\begin{array}{ll}w_{r} & =\text { radiation weighting factor } \\ \mathrm{RBE} & =\text { relative biological effectiveness number } \\ \mathrm{R}_{\mathrm{E}} & =\text { Earth radii }\end{array}$

\section{Introduction}

$\mathrm{T}_{\mathrm{s}}^{\mathrm{b}}$ here are three requirements for evaluating astronaut health risk due to space radiation exposure. The first is a description of the radiation environment external to the space vehicle or habitat including a fluence spectrum for each type of particle (electron, neutron, charged ion). Since the number of penetrating electrons is low in free space, the electron portions of the environments will be ignored. The second necessity for evaluating risk due to space radiation is a method of calculating how the external environment is altered by the vehicle. As charged ions pass through the materials making up the vehicle, they will lose energy. In addition, charged ions and neutrons can collide with the atomic nuclei of the shielding material producing secondary particles. This secondary particle environment could be, depending on the shielding material, more dangerous to humans than the primary environment outside the vehicle. Calculating the internal radiation environment, therefore, requires a model of the vehicle and a radiation transport code. The final requirement for evaluating radiation health risk to astronauts is a measure of how much is too much, i.e. exposure limits. In the past, these limits have been defined in terms of dose, dose equivalent, gray equivalent, and effective dose.

Sources of ionizing radiation exposure external to the vehicle or habitat for the subject missions arise from the galactic cosmic rays (GCR), geomagnetically trapped (Van Allen belt) protons, and protons and light ions from large solar proton events (SPEs). While some exposure from GCR ions and trapped protons will be unavoidable and while large SPE occurrence is rare, the SPE could be mission-threatening, and therefore becomes the major design driver for radiation protection. The lower-energy GCR component is markedly reduced with moderate shielding $(\sim 5$ $\mathrm{g} / \mathrm{cm}^{2}$ ), but even thick shields are not effective against the omnipresent very high energy (but low flux) particles. The trapped protons have energy spectral characteristics similar to the SPEs, but fluxes are generally lower, and direct rapid transit through the belt region $\left(1.2-3.0 \mathrm{R}_{\mathrm{E}}\right)$ should not result in hazardous exposure levels with provision of moderate protection. Orbiting in this region, however, should be avoided. Thus, for transit to and from the moon, inherent spacecraft structure and bulk (parasitic) shielding will generally provide enough protection from GCR and trapped contributions to mitigate radiation risk. However, for longer surface stays ( $>6$ months), risk due to GCR exposure must be evaluated and auxiliary shielding may be needed.

The purpose of these studies was not to create a plan for one lunar mission with complete vehicle designs, but to perform trade analyses comparing as many mission scenarios and vehicle geometries as possible. The question that arose was, "how much auxiliary shielding must be added to the transit vehicles and habitats to protect astronauts from large SPEs and GCR?" The answer, of course, is that it depends on the vehicle design and mission scenario. Without these details, only very rough estimates can be made. Here it was assumed that the transit vehicle would provide shielding similar to that of the Apollo capsule and dosimetry data for "worst case" environments for various shielding materials and thicknesses calculated with the HZETRN ${ }^{1}$ space radiation transport code was used. It is reasonable to question the usefulness of such a rough estimate. Certainly the numbers calculated in this study are no substitute for a complete vehicle analysis and were never intended to be a substitute. They do, however, provide preliminary mission planners with a conservative estimate of the mass of the auxiliary radiation shielding that will need to be launched into space.

Radiation exposure limits have not yet been defined for missions beyond low Earth orbit (LEO). For LEO operations, in addition to a federally mandated obligation to follow the ALARA principle of keeping exposure "as low as reasonably achievable," NASA has adopted and OSHA has approved the radiation exposure recommendations of the National Council on Radiation Protection and Measurements (NCRP) contained in NCRP Report No. $98^{2}$. This report contains monthly, annual, and career exposure limits in dose equivalent shown in Tables 1 and 2. Dose equivalent, $\mathrm{H}$, is defined by equation (1) as

$$
H=\int Q(L) D_{L} d L
$$

where $\mathrm{D}_{\mathrm{L}}$ is the dose from particles with linear energy transfer between $\mathrm{L}$ and $\mathrm{L}+\mathrm{dL}$ and $\mathrm{Q}(\mathrm{L})$ is a quality factor. 
Table 1. LEO exposure limits for blood forming organs, eyes, and skin for all ages (NCRP 98)

\begin{tabular}{|l|c|c|c|}
\hline & $\begin{array}{c}\text { BFO } \\
(\mathrm{Sv})\end{array}$ & $\begin{array}{c}\text { Eye } \\
(\mathrm{Sv})\end{array}$ & $\begin{array}{c}\text { Skin } \\
(\mathrm{Sv})\end{array}$ \\
\hline Career & See Table 2 & 4.00 & 6.00 \\
\hline Annual & 0.50 & 2.00 & 3.00 \\
\hline 30 Day & 0.25 & 1.00 & 1.50 \\
\hline
\end{tabular}

Table 2. LEO career BFO dose equivalent limits (Sv) (NCRP 98)

\begin{tabular}{|c|c|c|c|c|}
\hline Age & 25 & 35 & 45 & 55 \\
\hline Male & 1.5 & 2.5 & 3.2 & 4.0 \\
\hline Female & 1.0 & 1.75 & 2.5 & 3.0 \\
\hline
\end{tabular}

The NCRP has since recommended new exposure limits contained in NCRP Report No. $132^{3}$. These limits use the dosimetric quantities gray-equivalent and effective dose. Gray-equivalent, Gy-Eq, is used to evaluate health risk due to deterministic effects and is defined by equation (2) as

$$
\mathrm{Gy}-\mathrm{Eq}=\Sigma_{\mathrm{i}} \mathrm{RBE}_{\mathrm{i}} \mathrm{D}_{\mathrm{i}}
$$

where $\mathrm{RBE}_{\mathrm{i}}$ is the relative biological effectiveness for particle type $\mathrm{i}$ in the stated type of tissue and $\mathrm{D}_{\mathrm{i}}$ is the dose contribution (the energy transfer) of type i particles. Effective dose is a measure of whole body exposure and is used to evaluate health risk due to stochastic effects. Effective dose, E, is a weighted average of dose equivalent to various body organs and tissue sites as shown in equation (3).

$$
E=\Sigma w_{T} H_{T}
$$

where $H_{T}$ is the equivalent dose to organ $T$ and $w_{T}$ is the weight factor for that organ. The new exposure limits recommended by NCRP Report No. 132 are shown in Tables 3 and 4.

Table 3. LEO exposure limits for blood forming organs, eyes, and skin for all ages (NCRP 132)

\begin{tabular}{|l|c|c|c|}
\hline & $\begin{array}{c}\text { BFO } \\
(\mathrm{Gy}-\mathrm{Eq})\end{array}$ & $\begin{array}{c}\text { Eye } \\
(\mathrm{Gy}-\mathrm{Eq})\end{array}$ & $\begin{array}{c}\text { Skin } \\
(\mathrm{Gy}-\mathrm{Eq})\end{array}$ \\
\hline Career & See Table 4 & 4.00 & 6.00 \\
\hline Annual & 0.50 & 2.00 & 3.00 \\
\hline 30 Day & 0.25 & 1.00 & 1.50 \\
\hline
\end{tabular}

Table 4. LEO career whole body effective dose limits (Sv) (NCRP 132)

\begin{tabular}{|c|c|c|c|c|}
\hline Age & 25 & 35 & 45 & 55 \\
\hline Male & 0.7 & 1.0 & 1.5 & 3.0 \\
\hline Female & 0.4 & 0.6 & 0.9 & 1.7 \\
\hline
\end{tabular}

The career limits in Table 4 are based on a requirement that there be no more than a $3 \%$ excess career fatal cancer risk. These dose limits have a large biological uncertainty associated with them, however, as demonstrated in Fig. $1^{4}$.

New exposure limits for lunar missions may require a $95 \%$ confidence level of remaining below the $3 \%$ excess fatal cancer probability. Preliminary studies show that this may decrease allowable astronaut exposure time by up to a factor of 6 .

In the remainder of the paper, the need for auxiliary radiation protection in lunar transit vehicles and habitats will be discussed. This will begin with an examination of shielding needs for short term missions for which large solar proton event protection is the primary concern. Here, the rarity of these events as well as the danger they pose to humans will be considered. Then a method for making preliminary estimates of the mass of the necessary auxiliary SPE shielding will be mapped out and auxiliary shielding mass requirements will be calculated for lunar transit vehicles of varying sizes. The short term mission analyses will be followed by a discussion of shielding needs for long term surface stays for which GCR exposure is the primary concern. The radiation exposure for a 500-day lunar 
surface stay will be evaluated and compared to LEO dose limits. Then the effects of lowering career limits on mission duration and architecture will be analyzed. Lastly, methods for a more comprehensive radiation analysis once vehicle designs have been created will be discussed.

\section{Radiation Shielding for Lunar Transit Vehicles and Short Stay Habitats}

Here the shielding requirements for lunar transit vehicles and short stay lunar habitats are discussed. The following assumptions are made:

1) The transit time from Earth to the moon will be no more than 48 hours.

2) Astronauts will spend no more than 14 days on the lunar surface.

3) The return trip will take no more than 48 hours.

4) The transit vehicle will pass directly through the most intense part of the Van Allen Belt $\left(1.2-3.0 R_{E}\right)$. With these assumptions, protection from large SPEs becomes the primary concern.

\section{A. Large Solar Proton Events}

Large SPEs are relatively rare. Observations indicate that occurrences are limited to the $\sim 7$ years of solar active conditions within the $\sim 11$-year solar cycle, and that only 1 or 2 such events per cycle may be expected. Reliable data are only available for the last 5 decades, so statistics are accordingly crude. Events appear to occur randomly, and no reliable method presently exists for lead time prediction. A model for SPE spectral charactistics and occurrence probability has been recently developed by Xapsos, et al ${ }^{5}$ that defines worst-case SPEs. In this model, the 99 percentile worst case is well-approximated by 4 X spectral flux observed for the large SPE of Sept. 1989 for which the temporal and energy characteristics were well-defined by NOAA-GOES satellite measurements.

The probability of occurrence of a $4 \mathrm{X}$ Sept. ' 89 SPE during a non-solar minimum year is approximately $6(10)^{-6}$ per day. With model interpolation, reduction of flare intensity to 2 X Sept. ' 89 ( $~ 90$ percentile worst case) results in an occurrence probability of $6(10)^{-5}$ day $^{-1}$. The largest event on record with regard to high energy spectral characteristics is that which occurred in Feb. 1956 for which the pertinent measurements were made with groundlevel neutron monitors. Exposure from an event of this nature would exceed that of the Xapsos model 99 percentile event by approximately a factor of 2.5. Such an event may be reasonably considered as happening once or twice per century.

Finally, despite the low probability of occurrence, analysis of potential exposures from large SPEs indicates that doses incurred by the unprotected or under-protected astronaut may result in extreme radiation sickness or lethality. If a vehicle designed to protect astronauts during 4X Sept. 1989 event is exposed to an event similar to the Feb. 1956 event, astronauts would experience changes in blood count but no nausea and no fatalities. If a vehicle designed to protect astronauts during 2X Sept. 1989 event is exposed to an event similar to the Feb. 1956 event, astronauts would experience vomiting (might effect performance) but no fatalities. If a vehicle designed to protect astronauts during Sept. 1989 event is exposed to an event similar to the Feb. 1956 event, astronaut exposure could be lethal.

\section{B. Shield Protection Strategies}

For this study, the assumption was made that the dose limits for lunar missions will be similar to those for recommended in NCRP 132 for LEO operations. For large SPE exposures, the 30-day limit of 0.25 GrayEquivalent $(\sim 17 \mathrm{rad}$ for proton exposure) to $\mathrm{BFO}$ is of greatest significance for the subject missions and is taken as the critical design criterion for radiation protection.

For analysis of the lunar mission scenarios, a "nominal” SPE defined by 2X Sept. ' 89 intensity has been selected for which protection is provided such that LEO BFO limits are not exceeded. The cases for 4X and 1X Sept. '89 are also examined as part of the trade study. 


\section{Shield Preliminary Analysis for Estimates of Shield Mass Requirements}

A great number of simplifying assumptions have, of necessity, been made in the absence of vehicle configuration specification. Nevertheless, some relevant results concerning shield requirements have emerged. An approximate auxiliary shield mass was calculated in the following manner.

The first aspect was to take into account the vehicle structure. For a situation similar to Apollo, the propulsive element protects astronauts from radiation from one side as shown in Fig. 2. To account for this, one "side" of the radiation refuge is assumed to be provided by the propulsive module. The rest of the sides are assumed to be augmented by the module structure (Apollo/CM). An average of the protection provided by Apollo ${ }^{6}$ is assumed excluding the ablative region (already accounted for by the propulsion module). This number is $6.15 \mathrm{~g} / \mathrm{cm}^{2}$ $\left(12.6 \mathrm{lb} / \mathrm{ft}^{2}\right)$ of aluminum.

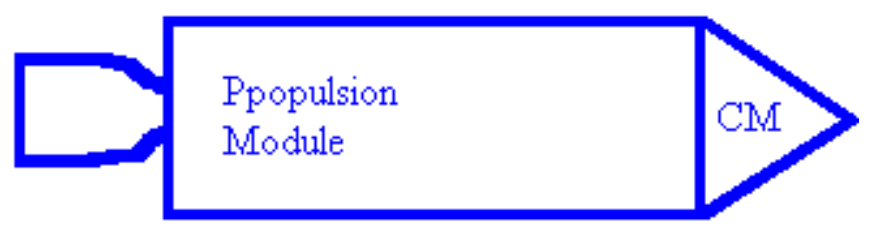

Figure 2. Command module and propulsion element.

Calculations using the LaRC space radiation transport code HZETRN show that protection for the 2X Sept. 1989 event based on spherical shielding (equal protection in all directions) requires approximately $11 \mathrm{~g} / \mathrm{cm}^{2}$ of aluminum. Similar calculations show that for shielding protons, polymeric material, e.g. polyethylene, may be used to reduce mass requirements based on aluminum shielding by approximately $20 \%$. Therefore, the remainder of the radiation refuge is assumed to be panels of varying thickness which can be assembled into a refuge as shown in Fig. 3 so that in every direction an equivalent of $11 \mathrm{~g} / \mathrm{cm}^{2}$ of aluminum shielding is provided. The panels might be stored against the walls or floor as additional micrometeoroid and orbital debris protection when not being used as a SPE "storm shelter". In considering a detailed design, the ability to displace other items to allow the assembly would have to be considered. The ability to displace the crews' normal operations would also have to be considered.

Based on this philosophy, the impacts of the radiation protection are calculated. Here, an average panel thickness was used in the calculation of the approximate shield mass. Additional protection is required for a $1 \mathrm{x}$ factor because of thin spots and a modified vehicle provision is assumed for the $1 \mathrm{x}$ factor. The primary goal of the protection is to protect the torso. Thinned protection is provided around the lower legs consistent with their vulnerability.

The assumptions and rationale that have been implemented as described produce the results given in Tables 5-7 for the 2, 4, and 6-person crews. Panel

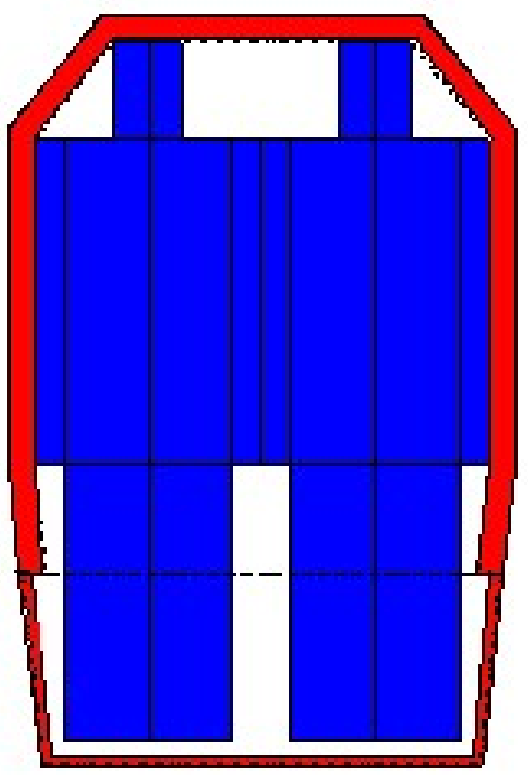

Figure 3. Radiation refuge for large SPE sizes are scaled to the statistical anatomical human for 95 percentile (tall), 50 percentile (average), and 5 percentile (short) and data is provided for protection for 1X Sept. ' 89 event, 2 X Sept. '89 event, and 4X Sept. ' 89 event. These tables allow mission planners to evaluate and compare the benefits of imposing size limits on crew members, reducing crew number, and reducing the amount of radiation protection. Note that for a crew of four 95 percentile astronauts, 4X Sept. '89 event would require $751 \mathrm{~kg}$ of added plastic bulk shielding. This mass could be reduced to $635 \mathrm{~kg}$ by sending smaller (average sized) astronauts. The auxiliary shielding mass could also be reduced to $565 \mathrm{~kg}$ by sending only two astronauts. The largest reduction in auxiliary shielding mass, however, is provided by reducing the level of protection provided. Auxiliary shielding for four 95 percentile astronauts to provide protection for $2 \mathrm{X}$ the Sept. '89 event is only $193 \mathrm{~kg}$, and if the protection level is reduced to $1 \mathrm{X}$ Sept. ' 89 , the auxiliary shielding mass is only $15 \mathrm{~kg}$. The cost of launching these materials will have to be balanced with the risk to astronauts and a design basis SPE will need be chosen. 
The manner in which these auxiliary shielding masses are provided is only notional and intended to provide a system level impact, not a final design. Ideally, the final design would be optimized so that the inherent features of the vehicle provide as much of the necessary shielding as possible and the auxiliary shielding mass is, therefore, minimized. Methods of evaluating the radiation protection provided by a vehicle or habitat, once the design phase of the mission planning has begun, are described in section $\mathrm{V}$.

Table 5. Auxiliary Shielding Mass for a 2 Crew Vehicle for 1X, 2X, and 4X September 28, 1989 SPE

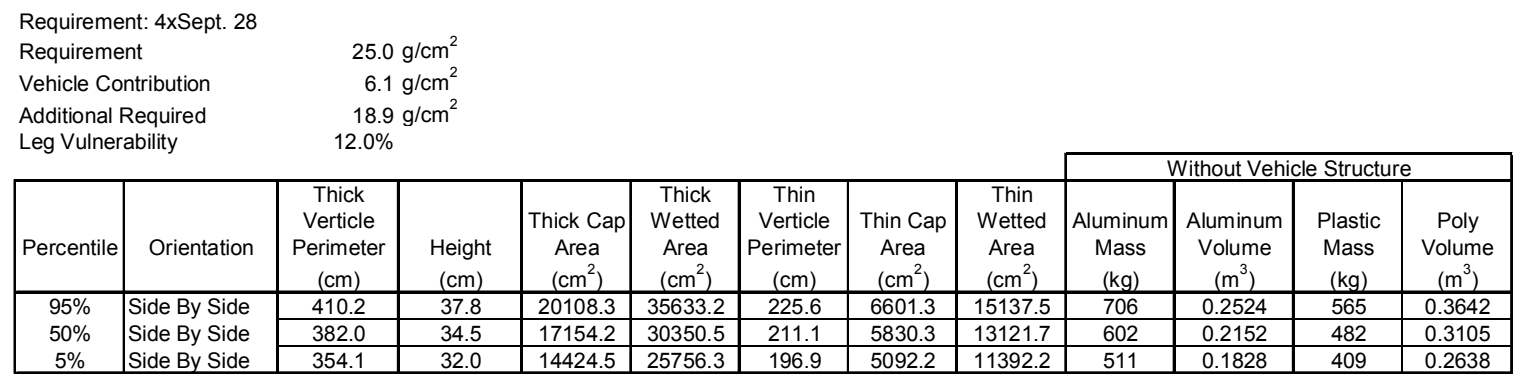

\begin{tabular}{|c|c|c|c|c|c|c|c|c|c|c|c|c|}
\hline \multicolumn{13}{|c|}{ Requirement: 2xSept. 28} \\
\hline \multirow{2}{*}{\multicolumn{2}{|c|}{$\begin{array}{l}\text { Requirement } \\
\text { Vehicle Contribution }\end{array}$}} & \multicolumn{2}{|c|}{$11.0 \mathrm{~g} / \mathrm{cm}^{2}$} & & & & & & & & & \\
\hline & & \multicolumn{2}{|c|}{$6.1 \mathrm{~g} / \mathrm{cm}^{2}$} & & & & & & & & & \\
\hline \multicolumn{2}{|c|}{$\begin{array}{l}\text { Additional Required } \\
\text { Leg Vulnerability }\end{array}$} & \multicolumn{2}{|c|}{$\begin{array}{l}4.9 \mathrm{~g} / \mathrm{cm}^{2} \\
12.0 \%\end{array}$} & & & & & & & & & \\
\hline & & & & & & & & & & Vithout Vehic & Structu & \\
\hline Percentile & Orientation & $\begin{array}{c}\text { Verticle } \\
\text { Perimeter } \\
(\mathrm{cm})\end{array}$ & $\begin{array}{l}\text { Height } \\
(\mathrm{cm})\end{array}$ & $\begin{array}{c}\text { Cap Area } \\
\left(\mathrm{cm}^{2}\right)\end{array}$ & $\begin{array}{c}\text { Thick } \\
\text { Wetted } \\
\text { Area } \\
\left(\mathrm{cm}^{2}\right) \\
\end{array}$ & \begin{tabular}{|c|} 
Thin \\
Verticle \\
Perimeter \\
$(\mathrm{cm})$ \\
\end{tabular} & $\begin{array}{c}\text { Thin Cap } \\
\text { Area } \\
\left(\mathrm{cm}^{2}\right) \\
\end{array}$ & $\begin{array}{c}\text { Thin } \\
\text { Wetted } \\
\text { Area } \\
\left(\mathrm{cm}^{2}\right) \\
\end{array}$ & $\begin{array}{c}\text { Aluminum } \\
\text { Mass } \\
(\mathrm{kg})\end{array}$ & $\begin{array}{c}\text { Aluminum } \\
\text { Volume } \\
\left(\mathrm{m}^{3}\right)\end{array}$ & $\begin{array}{c}\text { Plastic } \\
\text { Mass } \\
(\mathrm{kg}) \\
\end{array}$ & $\begin{array}{c}\text { Poly } \\
\text { Volume } \\
\left(\mathrm{m}^{3}\right)\end{array}$ \\
\hline \multirow{3}{*}{$\begin{array}{c}95 \% \\
50 \% \\
5 \% \\
\end{array}$} & \multirow{3}{*}{$\begin{array}{l}\text { Side By Side } \\
\text { Side By Side } \\
\text { Side By Side }\end{array}$} & 410.2 & 37.8 & 20108.3 & 35633.2 & 225.6 & 6601.3 & 15137.5 & 182 & 0.0650 & 145 & 0.0938 \\
\hline & & 382.0 & 34.5 & 17154.2 & 30350.5 & 211.1 & 5830.3 & 13121.7 & 155 & 0.0554 & 124 & 0.0800 \\
\hline & & 354.1 & 32.0 & 14424.5 & 25756.3 & 196.9 & 5092.2 & 11392.2 & 132 & 0.0471 & 105 & 0.0679 \\
\hline
\end{tabular}

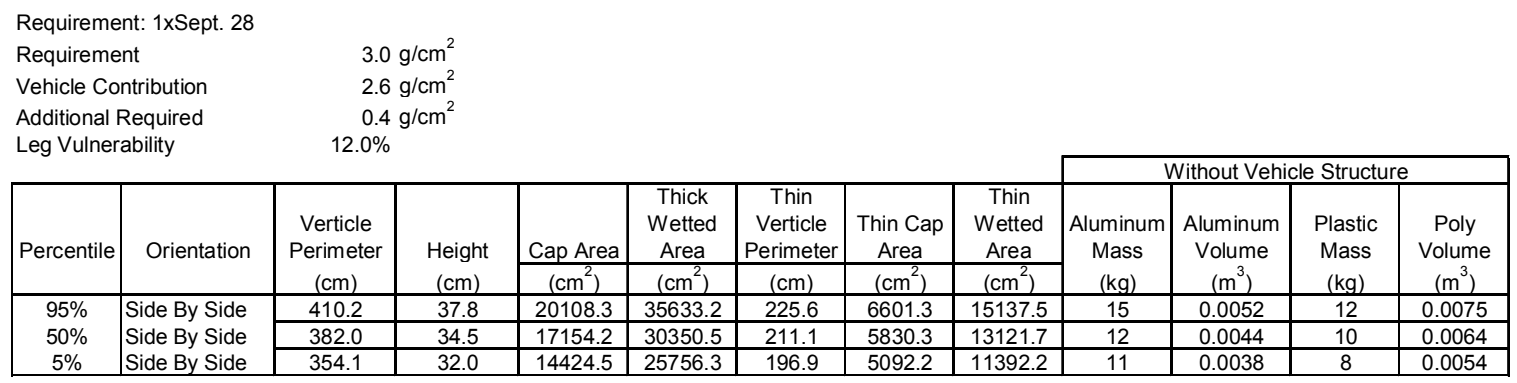


Table 6. Auxiliary Shielding Mass for a 4 Crew Vehicle for 1X, 2X, and 4X September 28, 1989 SPE

Requirement: $4 \times$ Sept. 28

$\begin{array}{lr}\text { Requirement } & 25.0 \mathrm{~g} / \mathrm{cm}^{2} \\ \text { Vehicle Contribution } & 6.1 \mathrm{~g} / \mathrm{cm}^{2} \\ \text { Additional Required } & 18.9 \mathrm{~g} / \mathrm{cm}^{2} \\ \text { Leg Vulnerability } & 12.0 \%\end{array}$

Leg Vulnerability

\begin{tabular}{|c|c|c|c|c|c|c|c|c|c|c|c|c|}
\hline \multirow[b]{2}{*}{ Percentile } & \multirow[b]{2}{*}{ Orientation } & & & & & & & & \multicolumn{4}{|c|}{ Without Vehicle Structure } \\
\hline & & $\begin{array}{c}\text { Thick } \\
\text { Verticle } \\
\text { Perimeter } \\
\text { (cm) }\end{array}$ & $\begin{array}{c}\text { Height } \\
(\mathrm{cm})\end{array}$ & $\begin{array}{c}\text { Thick Cap } \\
\text { Area } \\
\left(\mathrm{cm}^{2}\right) \\
\end{array}$ & $\begin{array}{c}\text { Thick } \\
\text { Wetted } \\
\text { Area } \\
\left(\mathrm{cm}^{2}\right) \\
\end{array}$ & \begin{tabular}{|c|} 
Thin \\
Verticle \\
Perimeter \\
$(\mathrm{cm})$ \\
\end{tabular} & $\begin{array}{c}\text { Thin Cap } \\
\text { Area } \\
\left(\mathrm{cm}^{2}\right) \\
\end{array}$ & $\begin{array}{c}\text { Thin } \\
\text { Wetted } \\
\text { Area } \\
\left(\mathrm{cm}^{2}\right) \\
\end{array}$ & $\begin{array}{c}\text { Aluminum } \\
\text { Mass } \\
(\mathrm{kg})\end{array}$ & $\begin{array}{c}\text { Aluminum } \\
\text { Volume } \\
\left(\mathrm{m}^{3}\right)\end{array}$ & $\begin{array}{c}\text { Plastic } \\
\text { Mass } \\
(\mathrm{kg}) \\
\end{array}$ & $\begin{array}{c}\text { Poly } \\
\text { Volume } \\
\left(\mathrm{m}^{3}\right) \\
\end{array}$ \\
\hline $95 \%$ & Side By Side & 410.2 & 66.0 & 20108.3 & 47198.6 & 225.6 & 6601.3 & 21496.7 & 939 & 0.3355 & 751 & 0.4841 \\
\hline $50 \%$ & Side By Side & 382.0 & 59.4 & 17154.2 & 39859.7 & 211.1 & 5830.3 & 18375.7 & 793 & 0.2835 & 635 & 0.4091 \\
\hline $5 \%$ & Side By Side & 354.1 & 54.4 & 14424.5 & 33670.6 & 196.9 & 5092.2 & 15792.2 & 671 & 0.2397 & 537 & 0.3459 \\
\hline
\end{tabular}

Requirement: 2xSept. 28

$\begin{array}{lr}\text { Requirement } & 11.0 \mathrm{~g} / \mathrm{cm}^{2} \\ \text { Vehicle Contribution } & 6.1 \mathrm{~g} / \mathrm{cm}^{2} \\ \text { Additional Required } & 4.9 \mathrm{~g} / \mathrm{cm}^{2} \\ \text { Leg Vulnerability } & 12.0 \%\end{array}$

Leg Vulnerability $\quad 12.0 \%$

\begin{tabular}{|c|c|c|c|c|c|c|c|c|c|c|c|c|}
\hline \multirow[b]{2}{*}{ Percentile } & \multirow[b]{2}{*}{ Orientation } & \multirow[b]{2}{*}{$\begin{array}{l}\text { Verticle } \\
\text { Perimeter } \\
\text { (cm) }\end{array}$} & \multirow[b]{2}{*}{$\begin{array}{l}\text { Height } \\
(\mathrm{cm})\end{array}$} & \multirow[b]{2}{*}{$\begin{array}{c}\text { Cap Area } \\
\left(\mathrm{cm}^{2}\right)\end{array}$} & \multirow[b]{2}{*}{$\begin{array}{c}\text { Thick } \\
\text { Wetted } \\
\text { Area } \\
\left(\mathrm{cm}^{2}\right)\end{array}$} & \multirow[b]{2}{*}{$\begin{array}{c}\text { Thin } \\
\text { Verticle } \\
\text { Perimeter } \\
\text { (cm) }\end{array}$} & \multirow[b]{2}{*}{$\begin{array}{c}\text { Thin Cap } \\
\text { Area } \\
\left(\mathrm{cm}^{2}\right)\end{array}$} & \multirow[b]{2}{*}{$\begin{array}{c}\text { Thin } \\
\text { Wetted } \\
\text { Area } \\
\left(\mathrm{cm}^{2}\right)\end{array}$} & \multicolumn{4}{|c|}{ Without Vehicle Structure } \\
\hline & & & & & & & & & $\begin{array}{c}\text { Aluminum } \\
\text { Mass } \\
(\mathrm{kg})\end{array}$ & $\begin{array}{c}\text { Aluminum } \\
\text { Volume } \\
\left(\mathrm{m}^{3}\right)\end{array}$ & $\begin{array}{c}\text { Plastic } \\
\text { Mass } \\
(\mathrm{kg})\end{array}$ & $\begin{array}{c}\text { Poly } \\
\text { Volume } \\
\left(\mathrm{m}^{3}\right)\end{array}$ \\
\hline $95 \%$ & Side By Side & 410.2 & 66.0 & 20108.3 & 47198.6 & 225.6 & 6601.3 & 21496.7 & 242 & 0.0864 & 193 & 0.1247 \\
\hline $50 \%$ & Side By Side & 382.0 & 59.4 & 17154.2 & 39859.7 & 211.1 & 5830.3 & 18375.7 & 204 & 0.0730 & 163 & 0.1054 \\
\hline $5 \%$ & Side By Side & 354.1 & 54.4 & 14424.5 & 33670.6 & 196.9 & 5092.2 & 15792.2 & 173 & 0.0617 & 138 & 0.0891 \\
\hline
\end{tabular}

Requirement: 1xSept. 28
Requirement
$3.0 \mathrm{~g} / \mathrm{cm}^{2}$
Vehicle Contribution
Additional Required
Leg Vulnerability

$$
0.4 \mathrm{~g} / \mathrm{cm}^{2}
$$$$
2.6 \mathrm{~g} / \mathrm{cm}^{2}
$$$$
12.0 \%
$$

\begin{tabular}{|c|c|c|c|c|c|c|c|c|c|c|c|c|}
\hline \multirow[b]{2}{*}{ Percentile } & \multirow[b]{2}{*}{ Orientation } & \multirow[b]{2}{*}{$\begin{array}{c}\text { Verticle } \\
\text { Perimeter } \\
\text { (cm) }\end{array}$} & \multirow[b]{2}{*}{$\begin{array}{l}\text { Height } \\
(\mathrm{cm})\end{array}$} & \multirow[b]{2}{*}{$\begin{array}{c}\text { Cap Area } \\
\left(\mathrm{cm}^{2}\right)\end{array}$} & \multirow[b]{2}{*}{$\begin{array}{c}\text { Thick } \\
\text { Wetted } \\
\text { Area } \\
\left(\mathrm{cm}^{2}\right)\end{array}$} & \multirow[b]{2}{*}{\begin{tabular}{|c} 
Thin \\
Verticle \\
Perimeter \\
(cm)
\end{tabular}} & \multirow[b]{2}{*}{$\begin{array}{c}\text { Thin Cap } \\
\text { Area } \\
\left(\mathrm{cm}^{2}\right)\end{array}$} & \multirow[b]{2}{*}{$\begin{array}{c}\text { Thin } \\
\text { Wetted } \\
\text { Area } \\
\left(\mathrm{cm}^{2}\right)\end{array}$} & \multicolumn{4}{|c|}{ Without Vehicle Structure } \\
\hline & & & & & & & & & $\begin{array}{c}\text { Aluminum } \\
\text { Mass } \\
(\mathrm{kg})\end{array}$ & $\begin{array}{c}\text { Aluminum } \\
\text { Volume } \\
\left(\mathrm{m}^{3}\right)\end{array}$ & $\begin{array}{c}\text { Plastic } \\
\text { Mass } \\
(\mathrm{kg})\end{array}$ & $\begin{array}{c}\text { Poly } \\
\text { Volume } \\
\left(\mathrm{m}^{3}\right)\end{array}$ \\
\hline \multirow{3}{*}{$\begin{array}{c}95 \% \\
50 \% \\
5 \%\end{array}$} & \multirow{3}{*}{$\begin{array}{l}\text { Side By Side } \\
\text { Side By Side } \\
\text { Side By Side }\end{array}$} & 410.2 & 66.0 & \begin{tabular}{|l|}
20108.3 \\
\end{tabular} & 47198.6 & 225.6 & 6601.3 & 21496.7 & 19 & 0.0069 & 15 & 0.0100 \\
\hline & & 382.0 & 59.4 & 17154.2 & 39859.7 & 211.1 & 5830.3 & 18375.7 & 16 & 0.0058 & 13 & 0.0084 \\
\hline & & 354.1 & 54.4 & 14424.5 & 33670.6 & 196.9 & 5092.2 & 15792.2 & 14 & 0.0049 & 11 & 0.0071 \\
\hline
\end{tabular}


Table 7. Auxiliary Shielding Mass for a 6 Crew Vehicle for 1X, 2X, and 4X September 28, 1989 SPE

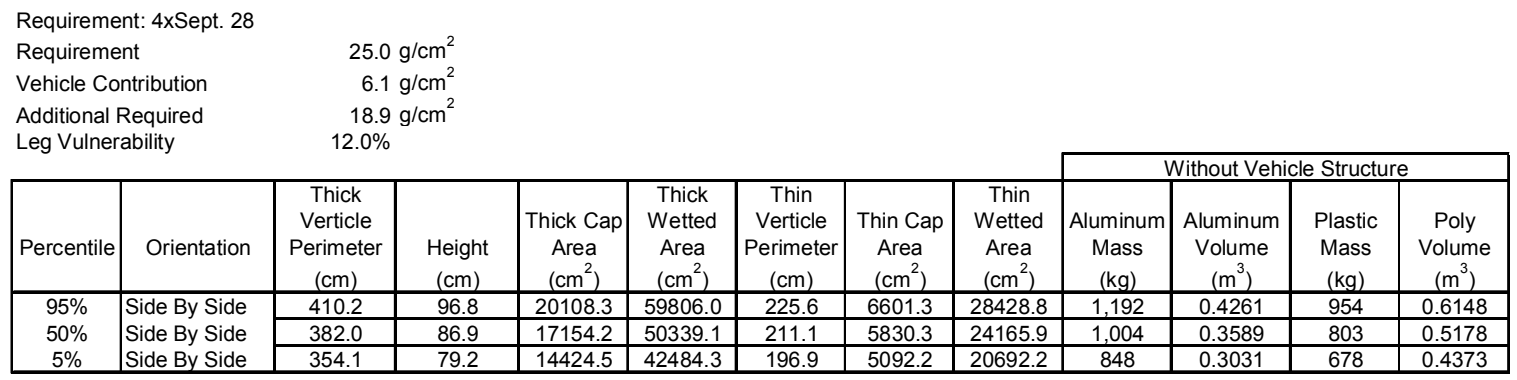

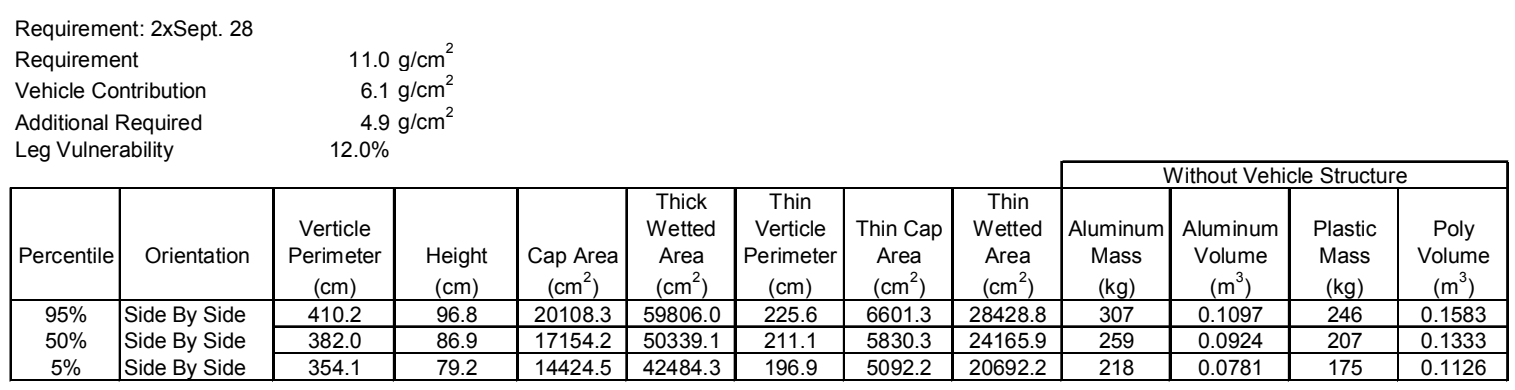

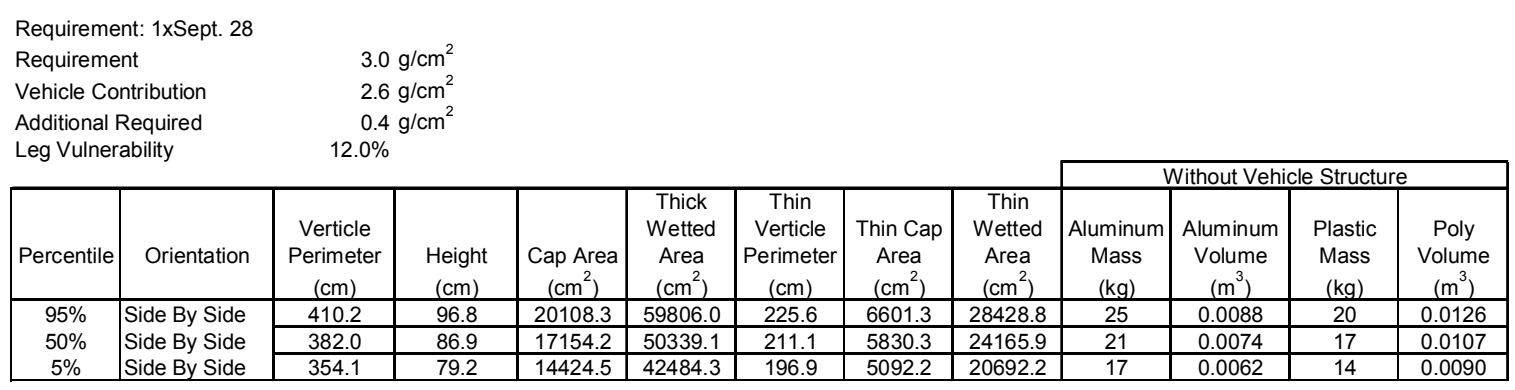

\section{GCR Radiation Exposure for a 500-Day Lunar Surface Stay}

Radiation exposure time for the astronauts can be broken into three categories: the Extravehicular Activities (EVA), the scientific and research activities, and the sleeping and personal time activities. Here the GCR exposure for the EVA portion of the astronaut activities is investigated, since that is the time the astronauts will be least protected.

The HZETRN space radiation transport code was used to calculate the maximum daily effective dose for an astronaut on the lunar surface to be $0.085 \mathrm{cSv}$. Here the Badhwar-O'Neill model of the 1977 solar minimum environment $^{7}$ was used as a worst case GCR environment and it was assumed that the EVA suits on the lunar surface provide no radiation protection. Therefore, a 500-day lunar expedition made up entirely of EVA would result in an astronaut exposure of $0.425 \mathrm{~Sv}$. While this is clearly an unrealistic scenario, it does provide an upper bound for radiation exposure on the lunar surface. Note that this calculation does not include the possibility of an SPE occurring. Table 8 shows this $0.425 \mathrm{~Sv}$ as a percentage of the career limits for LEO operations.

Table 8. 0.425 Sv Exposure as a Percentage of LEO Career Effective Dose Limits

\begin{tabular}{|l|c|c|c|c|}
\hline Age & 25 & 35 & 45 & 55 \\
\hline Male & $61 \%$ & $43 \%$ & $29 \%$ & $14 \%$ \\
\hline Female & $108 \%$ & $72 \%$ & $48 \%$ & $25 \%$ \\
\hline
\end{tabular}

This improbable worst case shows that for the NCRP 132 LEO requirements there is no limitation on the crew for prolonged exposure to radiation effects on the lunar surface. If the present requirements change due to the 
biological uncertainty, then a more detailed model including transit and habitation stay times will need to be analyzed. And if, in fact, exposure limits are decreased by a factor of 6 , radiation will become the limiting factor for a 500-day surface stay. Further, EVA hours could be limited for 90-day stays.

\section{GCR Radiation Exposure with 95\% Confidence Level of Remaining Below the 3\% Excess Fatal Cancer Probability}

As yet, only preliminary calculations have been performed to evaluate allowable exposure durations using this new criterion as shown in Table $9^{4}$.

Table 9. Allowable Days in Free Space at Solar Minimum Behind $10 \mathrm{~g} / \mathrm{cm}^{2}$ of Aluminum Shielding with a 95\% confidence of Remaining Below the 3\% Excess Fatal Cancer Risk

\begin{tabular}{|c|c|c|}
\hline Age (years) & Female & Male \\
\hline 30 & 54 & 91 \\
\hline 35 & 62 & 104 \\
\hline 40 & 73 & 122 \\
\hline 45 & 89 & 148 \\
\hline 50 & 115 & 191 \\
\hline 55 & 159 & 268 \\
\hline \multicolumn{2}{|c}{}
\end{tabular}

Note that these calculations were performed for the free space environment. An astronaut on the surface of the moon is protected from the GCR environment in $2 \pi$ directions by the lunar regolith. However, there are low energy neutrons and light ions produced as a result of interaction between the galactic cosmic rays and the lunar regolith that make a small contribution to astronaut dose. For these reasons, the radiation environment on the lunar surface is slightly more than half as intense as that of free space. Thus, the allowable days of exposure in a surface habitat that provides $10 \mathrm{~g} / \mathrm{cm}^{2}(\sim 3.7 \mathrm{~cm})$ of aluminum shielding would be approximately double those shown in Table 4 . This means that both male and female astronauts of any age could complete a 90-day lunar surface mission in a habitat with enough shielding, but the allowable number of EVA hours would be severely limited especially for young female astronauts. This also shows that $10 \mathrm{~g} / \mathrm{cm}^{2}(\sim 3.7 \mathrm{~cm})$ of aluminum would not be enough shielding for a 500day mission. In fact, if $95 \%$ confidence of staying below $3 \%$ excess fatal cancer risk is adopted as the exposure limit, a 500-day mission might require using the lunar regolith as a shielding material. This could be accomplished by building the habitat inside a lava tube or by putting regolith on top of the habitat.

\section{Incorporation of Radiation Analysis in the Design Process}

Once a preliminary habitat or vehicle design has been created, a radiation shielding analysis can be performed. CAD models can be converted into radiation shielding models and a ray tracing of these models can then be performed to calculate shielding thickness in all directions. As an example, Fig. 4 shows a shielding ray tracing of the ISS Service Module crew quarters. Once a ray tracing has been performed, the HZETRN radiation transport code can then be used to calculate the directionally dependant effective dose. Figure 5 shows a sample calculation for ISS. In this way, the shielding provided by the inherent features of the habitat can be assessed and design recommendations to provide more shielding while minimizing mass can be made. 


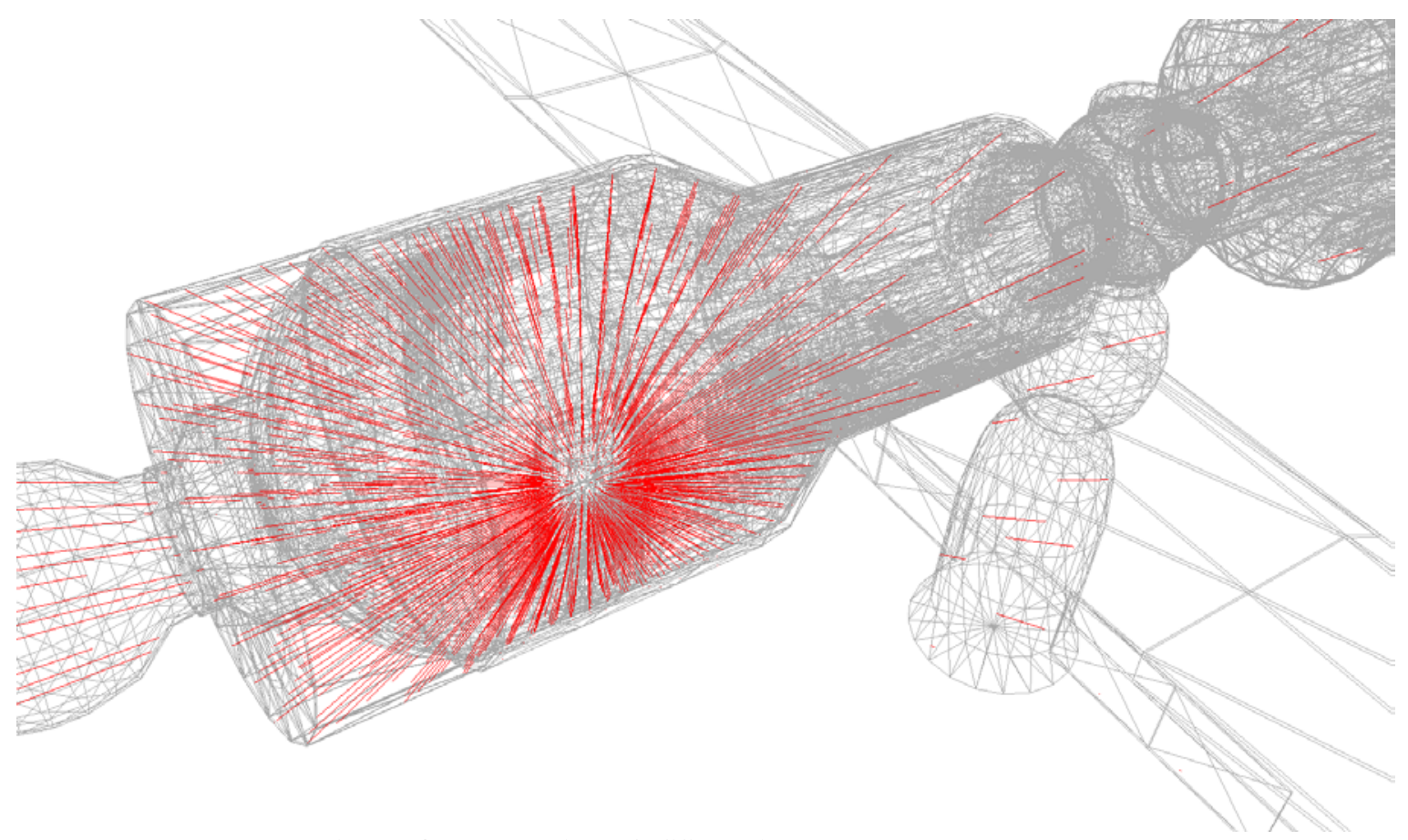

Figure 4. Ray tracing of ISS service module crew quarter.

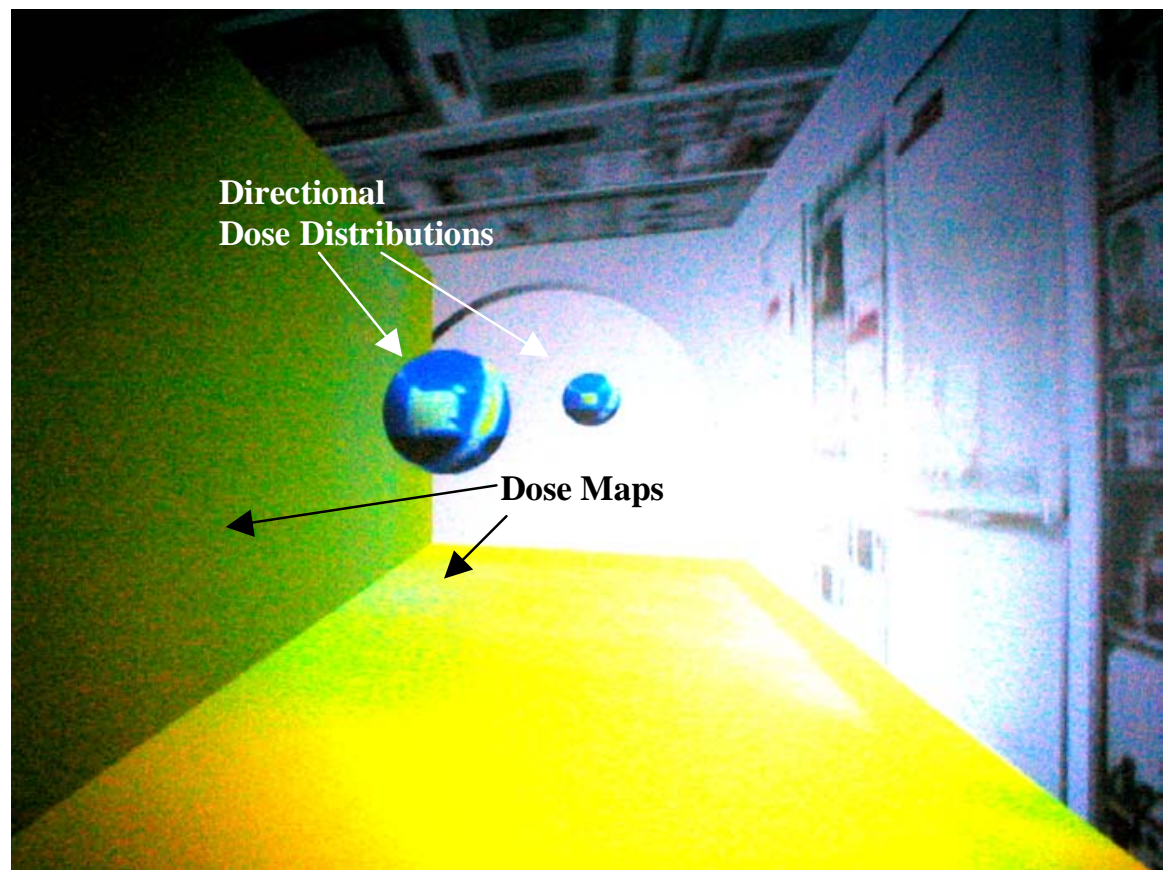

Figure 5. ISS directional dose distribution. 


\section{Summary}

Analyses have been performed to provide preliminary estimates of auxiliary radiation shielding masses for lunar transit vehicles. These calculations show that this auxiliary shielding mass could be as large as $954 \mathrm{~kg}$ or as small as $8 \mathrm{~kg}$ depending on the number of crew members, the size of the astronauts, and the level of solar proton event shielding provided. These calculations emphasized the need for a consensus to be formed on a design basis SPE. In addition, the radiation exposure that astronauts would incur on long term lunar surface missions was evaluated. These calculations highlighted the need for a consensus on exposure limits for lunar missions.

\section{References}

${ }^{1}$ Wilson, J. W., Badavi, F. F., Cucinotta, F. A., Shinn, J. L., Badhwar, G. D., Silberberg, R., Tsao, C. H., Townsend, L. W., and Tripathi, R. K., "HZETRN: Description of a Free-Space Ion and Nucleon Transport and Shielding Computer Program," NASA TP-3495, 1995.

2“Guidance on Radiation Received in Space Activities," NCRP Report No. 98, National Council on Radiation Protection and Measurements, Bethesda, MD, 1989.

3“"Radiation Protection Guidance for Activities in Low-Earth Orbit," NCRP Report No. 132, National Council on Radiation Protection and Measurements, Bethesda, MD, 2001.

${ }^{4}$ Cucinotta, F. A., Schimmerling, W., Wilson, J. W., Pererson, L. E., Badhwar, G. D., Saganti, P. B., and Dicello, J. E., "Space Radiation Cancer Risks and Uncertainties for Mars Missions," Rad. Res., Vol. 156, 2001, pp. 682-688 (2001)

${ }^{5}$ Xapsos, M. A., Barth, J. L.; Stassinopoulos, E. G.; Burke, E. A.; and Gee, G. B., "Space Environment Effects: Model for Emission of Solar Protons (ESP): Cumulative and Worst Case Event Fluences,” NASA TP-1999-209763, 1999.

${ }^{6}$ Burns, H. P. and Tinnan, L. M., "Extended-Mission Apollo Study. Volume IX - Space Environment, Structures, and Weights," NASA CR-56058, 1963.

${ }^{7}$ Badhwar, G. D., and O’Neill, P. M., Nucl. Tracks and Rad. Meas., 20, pp. 403-410, 1992. 